\title{
Traffic noise abatement: How different pavements, vehicle speeds and traffic densities affect annoyance levels
}

\author{
E. Freitas ${ }^{\mathrm{a}, *}$, C. Mendonça ${ }^{\text {b,d }}$, J.A. Santos ${ }^{\mathrm{b}, \mathrm{c}, \mathrm{d}}$, C. Murteira ${ }^{\mathrm{b}}$, J.P. Ferreira ${ }^{\mathrm{a}}$

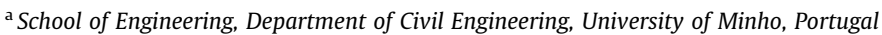 \\ ${ }^{\mathrm{b}}$ School of Psychology, Department of Basic Psychology, University of Minho, Portugal \\ ${ }^{\mathrm{c}}$ Centro Algoritmi, University of Minho, Portugal \\ ${ }^{\mathrm{d}}$ Centro de Computação Gráfica, Portugal
}

\section{A R T I C L E I N F O}

\section{Keywords:}

Traffic noise annoyance

Dense asphalt pavements

Open asphalt rubber pavements

Cobblestones pavements

\begin{abstract}
A B S T R A C T
In this paper, annoyance ratings from traffic noise recorded on cobblestones, dense asphalt, and open asphalt rubber pavements are assessed with regard to car speeds and traffic densities. It was found that cobblestones pavements are the most annoying; also while open asphalt rubber pavement imposes less annoyance than dense asphalt it is not significantly different. Higher car speeds always lead to greater annoyance, as does higher traffic densities. LAeq and LAmax correlate well with annoyance, but loudness is the best predictor. Roughness and sharpness exhibit inconsistent interactions.
\end{abstract}

(c) 2012 Elsevier Ltd. All rights reserved.

\section{Introduction}

Transportation is a major source of noise but few studies have been carried out on the impact of pavement type on noise annoyance, and most that have, have focused on porous asphalt and dense asphalt surfaces, (Sandberg and Ejsmont, 2002; Golebiewski et al., 2003). Additionally, many studies that have addressed noise annoyance taking into account traffic characteristics have disregarded the influence of road surface type (Griefahn et al., 2008; Paunović et al., 2009).

Here we seek to help establishing a better understanding of links between subjective annoyance ratings and traffic noise levels. Several acoustic measurements are considered when comparing road surfaces; not only LAeq (the equivalent continuous A-weighted sound pressure level) and LAmax (the A-weighted average of the maximum levels of the noise being investigated during a time interval), but also psychoacoustic indicators as loudness, roughness and sharpness.

\section{Materials and methods}

\subsection{Pavement surfaces}

We focus on three types of pavement:

- Cobblestones, that is often used in European city centres;

- Dense asphalt, that has been used for many years and can be taken as a reference surface; and

- Open graded asphalt rubber, that has been used in the last decade to delay cracking reflection and reduce rutting (Fontes et al., 2010), and to reduce noise (Donovan, 2005; Paje et al., 2010).

\footnotetext{
* Corresponding author.

E-mail address: efreitas@civil.uminho.pt (E. Freitas).
} 
Table 1

Main characteristics of the surfaces.

\begin{tabular}{llll}
\hline Type of surface & Cobblestones & Dense asphalt & Open asphalt rubber \\
\hline Maximum aggregate size & $100 \times 100 \mathrm{~mm}^{2}$ & $16 \mathrm{~mm}$ & $10 \mathrm{~mm}$ \\
Voids content $(\%)$ & - & $(3-5)$ & $(10-17)$ \\
Rubber content by bitumen weight $(\%)$ & - & - & $(18-20)$ \\
Mean profile depth $(\mathrm{mm})$ & - & 1 & 1.0 \\
Age (years) & $>20$ & 4 \\
\hline
\end{tabular}

Table 2

Noise levels (ordinary vehicles/hybrid vehicle) obtained by CPB method.

\begin{tabular}{lllll}
\hline Type of surface & LAmax $(\mathrm{dBA})$ & & \\
\cline { 2 - 5 } & $30(\mathrm{~km} / \mathrm{h})$ & $40(\mathrm{~km} / \mathrm{h}))$ & $50(\mathrm{~km} / \mathrm{h})$ & $60(\mathrm{~km} / \mathrm{h})$ \\
\hline Cobblestones & $68.4 / 65.3$ & $72.6 / 70.0$ & $75.8 / 73.7$ & $78.5 / 76.7$ \\
Dense asphalt & $63.9 / 59.6$ & $67.5 / 63.9$ & $70.2 / 67.2$ & $72.5 / 69.8$ \\
Open asphalt rubber & $63.2 / 60.5$ & $66.7 / 64.2$ & $69.5 / 67.1$ & $71.8 / 69.4$ \\
\hline
\end{tabular}

Table 3

Surface and air temperatures at testing time.

\begin{tabular}{lccc}
\hline Type of surface & Cobblestones & Dense asphalt & Open asphalt rubber \\
\hline Air temperature $\left({ }^{\circ} \mathrm{C}\right)$ & 11.1 & 8.6 & 18.1 \\
Surface temperature $\left({ }^{\circ} \mathrm{C}\right)$ & 6.0 & 12.6 & 29.8 \\
\hline
\end{tabular}

The vehicles used in the recordings are a small passenger car (Volkswagen Polo), a hybrid (Toyota Prius), and a pickup truck (Mitsubishi Strakar). Representative sections of the road surfaces and the recording methods follow the European ISO Standard 11819-1:1997. Road noise was binaurally recorded with a Brüel \& Kjaer Head and Torso Simulator (HATS) type 4128-C, a Brüel \& Kjaer Pulse Analyzer type 3560-C and Pulse CPB Analysis software. Speed measurements of each vehicle were obtained with Ultra Lyte LTI 20-20 radar.

The noise samples were recorded with the HATS at $7.5 \mathrm{~m}$ from the road centre and at a height of $1.7 \mathrm{~m}$. The controlled pass-by method $(\mathrm{CPB})$ was used. Each single vehicle tyre-road noise was recorded with variable speed profiles. Vehicle speeds were of 30,40,50, 60 and $70 \mathrm{~km} / \mathrm{h}$. To minimise the meteorological bias all recording sessions were performed with dry pavements, wind speed below $5 \mathrm{~m} / \mathrm{s}$, atmospheric temperature between $5^{\circ} \mathrm{C}$ and $30^{\circ} \mathrm{C}$, and pavement temperature between $5{ }^{\circ} \mathrm{C}$ and $50{ }^{\circ} \mathrm{C}$ as recommended in ISO Standard 11819-1:1997.

The main pavement characteristics influencing traffic noise of each surface are presented in Table 1 (Sandberg and Ejsmont, 2002). There is a difference in physical characteristics between dense asphalt and the open asphalt rubber but this only leads to differences of less than $1 \mathrm{~dB}(\mathrm{~A})$ (Table 2), estimated from the LAmax using the controlled pass-by method and the logarithm (base 10) of the measured speed. If corrections to the temperature effect are made, these differences may be even smaller (Table 3).

Further, the effect of age should not be discarded. Dense asphalt surface layers typically have higher noise levels at the beginning of their lifetime but are more stable with time as opposed to thin layers (Bendtsen et al., 2010), such as the open graded asphalt rubber, which is characterised by lower noise levels at the beginning of their lifetime and a significant increase of noise in their first years of service.

\subsection{Experiment}

Ninety-six listeners participated in the experiment aged 7-86 years with an average of 37 years, 26 were 19 years and under, 32 were $20-39,18$ were $40-59$, and 20 were 60 years and over. They were all voluntary participants, recruited from educational and social institutions in the area where the noise samples were taken. To exclude prior major hearing deficiency all participants underwent audiometric screening tests $(250,1000$ and $4000 \mathrm{~Hz})$

The single vehicle recordings were factorially paired by audio software (Ardour) to produce the stimuli for the annoyance assessment. For each pavement type and vehicle speed, from 30 to $70 \mathrm{~km} / \mathrm{h}$ with $10 \mathrm{~km} / \mathrm{h}$ increments, two traffic density compositions were defined (simulating a $2 \times 1 \mathrm{road}$ ). Traffic composition 1 (TC1) had five vehicles (three small passenger cars, one hybrid and one pickup truck) spaced $2.5 \mathrm{~s}$ from each other. Traffic composition two (TC2) had 15 vehicles (nine small passenger cars, three hybrids, three pickup trucks) spaced $1 \mathrm{~s}$ from each other. Therefore there were a total of $30 \mathrm{stim}$ uli (three pavements $\times$ five speeds $\times$ two traffic compositions). Each stimulus had the duration of five seconds. 
The stimuli were presented through a custom built $\mathrm{C}++$ application, running in a computer with a sound card Intel 82801BA-ICH2, and AKG K 271 MKII closed headphones. This system was calibrated to achieve sound pressure levels identical to those found in the original road environments. The values of LAmax, LAeq, sharpness, roughness, and loudness were assessed with the Psysound3 application (Cabrera et al., 2008).

The annoyance assessment of each participant was performed in a quiet room. All 30 stimuli were also presented channel reversed to avoid interaural biases. The resulting 60 samples were repeated twice. Thus each participant listened to 120 noise trials (30 stimuli $\times 2$ channel sequences $\times 2$ trials). Trials were presented in a pseudo-random order (method of the constant stimulus) to reduce anticipation and expectation interferences. Participants were requested to assess the annoyance of each noise trial with a ten-graded interval scale from one (less annoying) to ten (very annoying). The interval between trials is varied and depended on the promptness of participants. After the answer to a trial is recorded by pressing a number on a keyboard, the next noise sample is presented. Each session, with the 120 trials, lasts for about 14 min per participant.

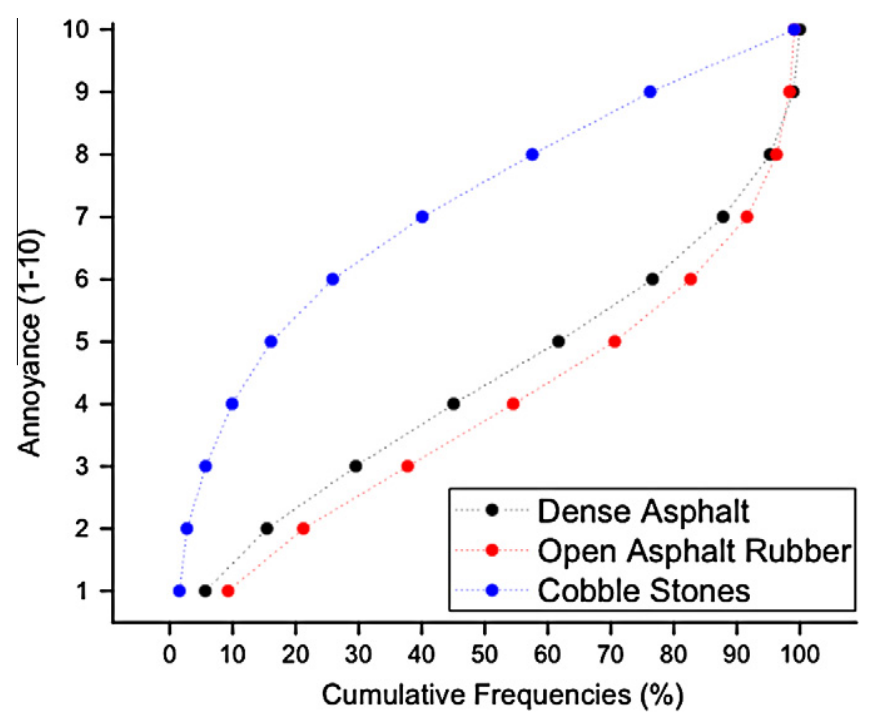

Fig. 1. Cumulative frequencies for the dense asphalt, open asphalt rubber, and cobblestones and annoyance assessment.

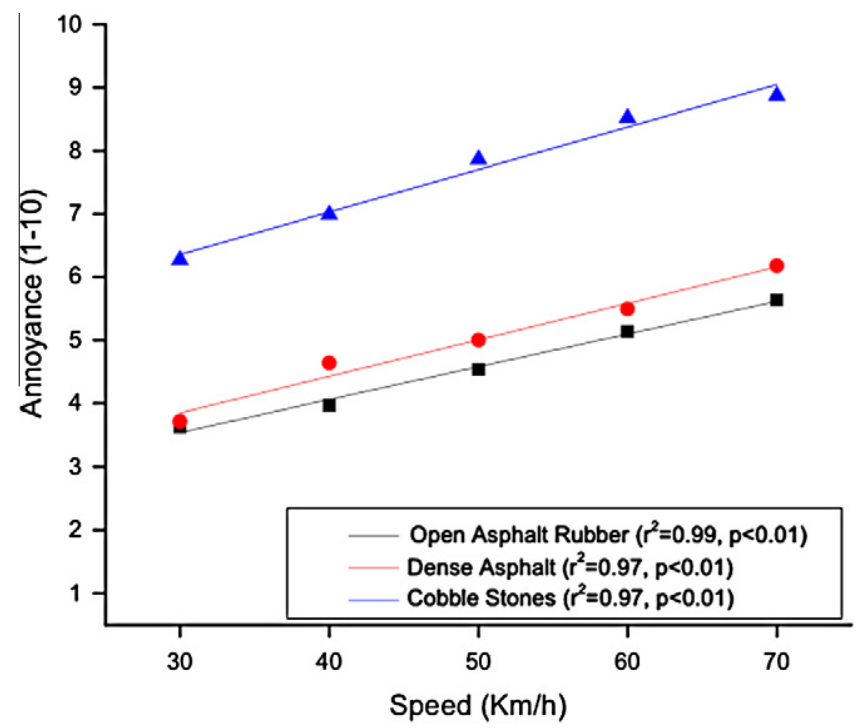

Note: 768 trails per dot

Fig. 2. Annoyance results for speed and pavement. 


\section{Results}

\subsection{Pavement, speed and traffic composition}

A preliminary analysis of the data, intra and inter-participants, revealed a high consistency of annoyance rates as a function of the main variables (pavement, speed and traffic composition). The results were also similar across all age groups: the juvenile had a mean annoyance of 5.59; the early adults had a mean of 5.79; middle adults had 5.47; and late adults had 5.60. These results did not differ significantly. Therefore, unless otherwise stated, the following data analyses are based upon the pooled data of the trials of all participants.

The pooled data per pavements, 3840 trials, points to a small difference of mean annoyance between the dense asphalt and open asphalt rubber pavements. The cobblestones pavement induces the highest rate of annoyance. Percentile 85 indicates the same trend with annoyance values of seven for both dense asphalt and open asphalt rubber, and 10 for the cobblestones pavement. Cumulative frequencies analysis also suggests that annoyance rises steeply for the cobblestone pavement, while both the dense and open asphalt rubber pavements follow a smoother and similar path (Fig. 1).

The analysis of the speed-pavement interactions reveals a linear increase of the mean annoyance as a function of speed (Fig. 2) with similar slopes for all pavements (cobblestones, 0.07; dense asphalt, 0.06; open asphalt rubber, 0.05). Again, the cobble pavement shows the highest rates of annoyance. The dense asphalt and open asphalt rubber pavements have similar rates (mean differences not exceeding 0.5); but with a consistent lower level of annoyance for the open asphalt rubber pavement.
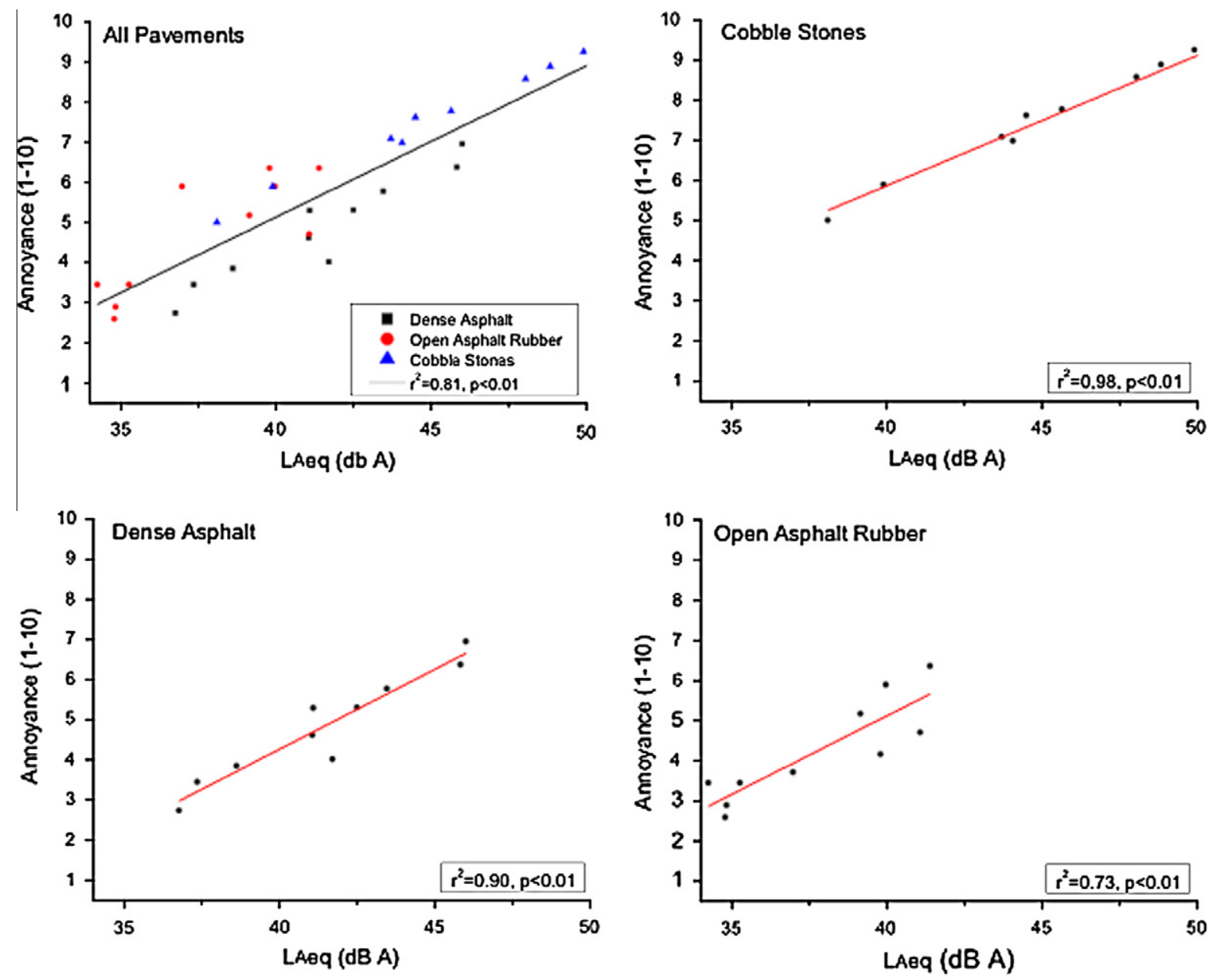

Note: 384 trials per dot.

Fig. 3. Linear regressions of LAeq values and the corresponding annoyance rates for all pavements separately for various types of pavement. 
The relation between speed and pavement type over annoyance ratings was statistically significant. Post-hoc Sheffé test revealed that this difference was significant between the open asphalt rubber and the cobblestones pavement, as well as between dense asphalt and cobblestones. The difference remained not significant between open asphalt rubber and dense asphalt.

In a similar way as found for the traffic speed, the traffic density composition also had an effect over annoyance rates for all pavements, with an increase of the mean annoyance as a function of the density. In line with both the global analysis per pavement and the speed-pavement results, the cobblestones pavement shows the highest rates of annoyance with mean values of 6.8 first (TC1) and 8.5 for the second (TC2) traffic compositions. The dense and open asphalt rubber pavements again have very similar mean rates with mean differences of neither exceeding 0.6 . The analysis of $85 \%$ percentile reveals identical patterns of annoyance variation and magnitude. For the cobblestones pavement, the TC1 and TC2 values are nine and ten. For the other pavements, the percentile values being six and eight for the dense asphalt, and of five and seven for the opens asphalt rubber.

The relation between pavement and traffic composition is statistically significant, and in the post hoc Sheffé test significant differences again were found between cobble and dense asphalt as well as cobble and open asphalt rubber. No difference was found between dense and open asphalt rubber.

Summarising, all age groups rate traffic noises according to the same standards. Cobblestones pavement lead to more annoying traffic noises than dense asphalt and open asphalt rubber. Open asphalt rubber noise is consistently less annoying than dense asphalt, but these differences are of low magnitude and are not statistically significant. Vehicle speed has a strong relation with annoyance for all pavement types. Traffic composition also has a clear effect over results, with higher density traffic scenes consistently leading to higher annoyance rates.
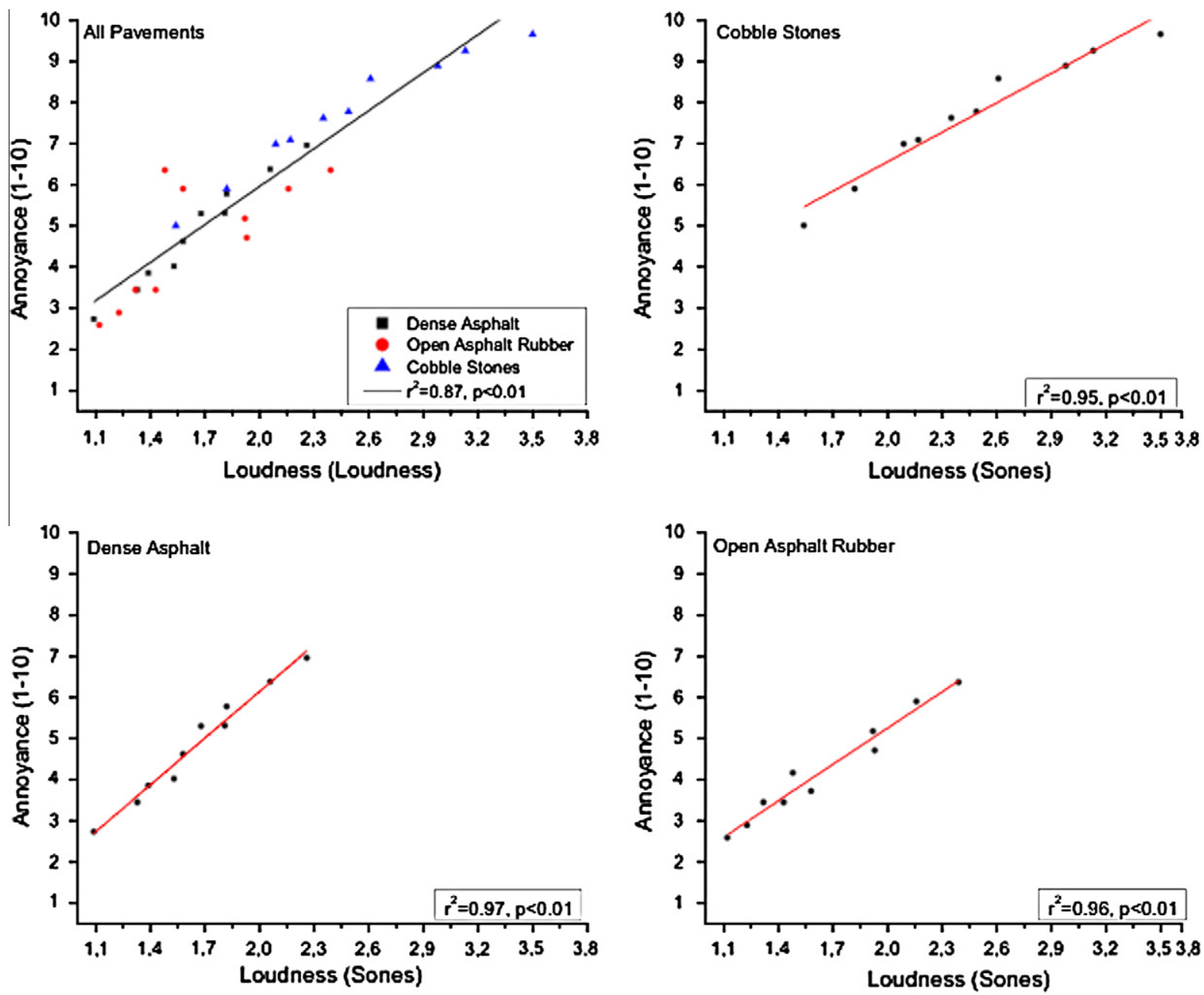

Note: 384 trials perdot.

Fig. 4. Linear models of loudness values and the corresponding annoyance rates for all pavements and separately for various types of pavement. 


\subsection{Annoyance and acoustic indicators}

To better understand, predict and compare how the different pavements impact annoyance ratings, several acoustic measurements were evaluated, namely LAeq, LAmax, loudness, roughness and sharpness. The pooled annoyance results seen in Fig. 3 suggest strong correlations between for all pavements together, and each type separately.

Results for LAmax are not as consistent as for LAeq. The linear relationship for all pavement types is relatively fit, mainly because of disparities in values of the pavements. Taken separately, the dense asphalt pavement result do not correlate with LAmax, while the cobblestones show a weak interaction and the open asphalt rubber obtains a value equal to that obtained with LAeq. The loudness analysis reveals the best fitting results (Fig. 4). Loudness explains well the annoyance ratings for the pooled data of all pavements. Considering each pavement separately, only the cobblestones ratings correlate less with loudness than with LAeq. Both the dense and open asphalt rubber annoyance are better predicted by loudness than by LAeq.

Sound roughness does not explain annoyance as well as loudness or LAeq, and nor does it explain the annoyance ratings of cobblestones, but it still has some predictability for dense asphalt and more so for open asphalt rubber. Roughness values distinguish the cobblestones pavement from both the dense asphalt and the open asphalt rubber. The first reveals consistently higher roughness levels, whereas the others have similar values. Sharpness analysis was also conducted, although linear regression analyses show barely any interaction between this psychoacoustic factor and annoyance. Again, dense and open asphalt rubber overlap in values and they are not predicted by sharpness. As opposed to the roughness interactions, only cobblestones has a clear relation with sharpness.

In sum, several acoustic properties of the tyre-road noise show an interaction with the annoyance ratings. LAeq correlates well with the annoyance, but it is loudness that best predicts traffic annoyance. Interestingly, not all factors interact equally with each pavement. LAmax values do not predict the dense asphalt annoyance ratings. Roughness might have a relation with dense asphalt and open asphalt rubber pavement noises, but not with cobblestones. Conversely, Sharpness relates with cobblestones traffic annoyance, but it does not predict either dense asphalt or open asphalt rubber results.

\section{Conclusion}

Approaching our findings from a practical point of view, three key factors associated to noise abatement should be considered: pavement type, traffic speed and traffic density. The relation between pavement type and traffic noise abatement should be taken cautiously. Cobblestones pavements have traditionally been used in city centres in Europe and in residential zones, and are still currently used as an option for aesthetical purposes in some areas. In part because these pavements are not the most comfortable to travel and because of noise considerations, over substantial investments have been made in new asphalt rubber mixtures. Although the noise reduction cannot be contested, it should be stressed that the perceived differences by users might not be as significant as expected. A cost-effective approach to reduce noise-related discomfort should also consider traffic speed and density, two factors that in this study revealed a consistent effect on annoyance ratings. Finally, traffic-related annoyance is best predicted by loudness indicators. Other sound measures might correlate with annoyance, but not as robustly across all pavement types.

\section{Acknowledgements}

This study was financed by the Portuguese Foundation for Science and Technology and FEDER, Projects FCOMP-01-0124FEDER-007560, FCOMP-01-0124-FEDER-022674 and PEst-OE/ECI/UI4047/2011.

\section{References}

Bendtsen, H., Kohler, E., Lu, Q., Rymer, B., 2010. California-Denmark study on acoustic aging of road pavements. Transportation Research Record 2158, 122128.

Cabrera, D., Ferguson, S., Rizwi, F., Schubert, 2008. Psysound 3 a program for the analysis of sound recordings. In: Proceedings of Acoustics. IEE, Paris.

Donovan, P., 2005. Comparative Measurements of Tire/Pavement Noise in Europe and the United States, the NITE-Study. California Department of Transportation/Illingworth \& Rodkin, Inc., Sacremeto.

Fontes, L., Trichês, G., Pais, J., Pereira, P., 2010. Evaluating permanent deformation in asphalt rubber mixtures. Construction and Building Materials 24, 11931200.

Golebiewski, R., Makarewicz, R., Nowak, M., Preis, A., 2003. Traffic noise reduction due to the porous road surface. Applied Acoustics 64, 481-494.

Griefahn, B., Gjestland, T., Preis, A., 2008. Annoyance of Residents Living in Urban Areas. Report to Partners Deliverable A.D6: Month 36 SILENCE Integrated Project - Contract N. 516288: European Commission, Brussels.

Paje, S., Bueno, M., Terán, F., Miró, R., Pérez-Jiménez, F., Martínez, A., 2010. Acoustic field evaluation of asphalt mixtures with crumb rubber. Applied Acoustics Journal 71, 578-582.

Paunović, K., Jakovljević, B., Belojević, G., 2009. Predictors of noise annoyance in noisy and quiet urban streets. Science of the Total Environment 407, 37073711.

Sandberg, U., Ejsmont, J., 2002. Tyre-Road Noise Reference Book. Informex SE-59040 Kisa. 